\title{
Mechanism of the Products Formation in the Vapor Phase Ammoxidation Reaction of 4-Phenyl-o-Xylene
}

\author{
Gulu A. Bagirzade, Dilgam B. Tagiyev, Manaf R. Manafov \\ Institute of Catalysis and Inorganic Chemistry Named after M. Nagiyev, National Academy of \\ Sciences of Azerbaijan, Baku, Azerbaijan \\ Email: mmanafov@gmail.com
}

Received 30 June 2015; accepted 7 October 2015; published 12 October 2015

Copyright (C) 2015 by authors and Scientific Research Publishing Inc.

This work is licensed under the Creative Commons Attribution International License (CC BY). http://creativecommons.org/licenses/by/4.0/

c) (7) Open Access

\begin{abstract}
On the basis of kinetic data of 4-phenyl-o-xylene and 4-phenyl-o-tolunitrile ammoxidation, formation mechanism of the products was analyzed and generalized. It has been shown that dissociative adsorption of a substrate and mononitrile occurs on the centers with high heats of adsorption of oxygen and as a consequence, completely covered with it, competitive adsorption of $\mathrm{NH}_{3}$ and $\mathrm{O}_{2}$ occurs on the centers with low heats of adsorption of the latter; mononitrile and dinitrile are formed correspondingly from adsorbed fragments of both substrate and $\mathrm{NH}_{3}$, and tolunitrile and $\mathrm{NH}_{3}$; surface interaction of adsorbed fragments of substrate and $\mathrm{O}_{2}$ with low heat of adsorption gives imide and $\mathrm{CO}_{2}$; hydrolysis of dinitrile into imide occurs on centers completely covered with ammonia; imide decarboxylation occurs on the centers covered with it; oxidative destruction of tolunitrile occurs on centers covered with substrate and mononitrile.
\end{abstract}

\section{Keywords}

Ammonolysis, 4-Phenyl-o-Xylene, Kinetics, Mechanism

\section{Introduction}

In papers [1] [2] kinetic regularities of vapor phase catalytic ammoxidation of both a substrate-4-phenyl-o-xylene and an intermediate 4-phenyl-o-tolunitrile were studied. A following scheme of conversions, constituting a total process of 4-phenyl-o-xylene ammoxidation on $\mathrm{V}$-Sb-Bi- $\mathrm{Zr} / \gamma-\mathrm{Al}_{2} \mathrm{O}_{3}$-oxide catalyst (Figure 1), was proposed in contributions [1] [3] [4]. The old analog wearing a patent character [5] exists in this field; however, the kinetic regularities of 4-phenyl-o-xylene ammoxidation on $\mathrm{V}_{2} \mathrm{O}_{5}-\mathrm{CrO}_{3} / \gamma-\mathrm{Al}_{2} \mathrm{O}_{3}$ catalyst have not been studied 


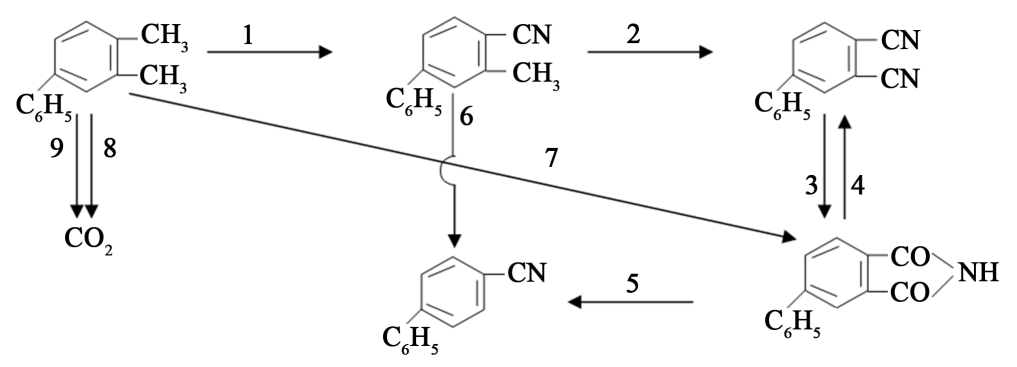

Figure 1. The complete conversion of 4-phenyl-o-xylene under ammoxidation.

and a mechanism of products formation on the basis of kinetic data has not been discussed by authors. In paper [6] the main routes of catalytic oxidative conversions of some methyl derivatives of biphenyl in the gas phase, including 3,4-dimethylbiphenyl (4-phenyl-o-xylene) ammoxidation, were studied. In the patent [5] it is shown that for $10 \%$ of $\mathrm{V}_{2} \mathrm{O}_{5}-5.6 \% \mathrm{CrO}_{3} / \gamma-\mathrm{Al}_{2} \mathrm{O}_{3}$ catalyst at a temperature of $693 \mathrm{~K}$ and a molar ratio of 4-phenyl-o-xylene: $\mathrm{NH}_{3}: \mathrm{O}_{2}$, equal to 1:39.71:6 turns out 4-phenylphthalonitrile with the $70 \%$ yield and conversion of the substrate in this case is $99 \%$. Study of vapor oxidation and ammoxidation of 3,4-di-and 3,3', 4,4'-tetramethyldiphenyls enables obtaining of the corresponding acid anhydrides, imides, nitriles of biphenylcarboxylic acids in a yield of $59-69 \mathrm{~mol} \%$ [6]. The ammoxidation on many oxide catalysts is the exothermic catalytic reaction of o-xylene accompanied by the formation of major products, nitrites and imides. Therefore, an important object of research in the ammoxidation of xylene, and 4-brom- and 4-phenyl-o-xylene is the solution of the selectivity of the corresponding dinitrile and imide [7]. As a result of own study, it has been found that on the $\mathrm{V}-\mathrm{Sb}-\mathrm{Bi}-\mathrm{Zr} / \gamma$ $\mathrm{Al}_{2} \mathrm{O}_{3}$-oxide catalyst, at high conversion of the starting 4-phenyl-o-xylene in single process [8] [9], ammoxidation gives $80 \mathrm{~mol} \%$ of 4-pfenylftalonitrile. Due to increased demands on the purity of the 4-pfenylftalonitrile while using and problem of the separation of hard separable impurities in the crystal 4-phenylftalimide, the variant of the technological design process with an average conversion and recycling unreacted 4-phenyl-o-xylene and intermediate 4-phenyl-o-tolunitrile is offered. In contrast to the single process, conducting of process with recirculation reduces quantity of the formed by-products, the share of deep oxidation and increases selectivity on a 4- phenyl phthalonitrile to $97.72 \%$ [8].

Thus, the problem of the separation of hard separable crystal mixture of main products has been solved in the case of obtaining dinitrile from the substrate with the average conversion on the V-Sb-Bi- $\mathrm{Zr} / \gamma-\mathrm{Al}_{2} \mathrm{O}_{3}$-oxide catalyst, with the recirculation at higher concentrations of ammonia, and in the synthesis of imide with complete conversion of the substrate in a single process on $\mathrm{V}-\mathrm{Sb}-\mathrm{Bi}-\mathrm{Zr} / \gamma-\mathrm{Al}_{2} \mathrm{O}_{3}$-oxide catalyst, using low concentrations of ammonia and water in the initial reaction mixture [9] [10]. As known, in general, and especially in cases where basic products are formed by competing pathways, to direct the reaction towards the important target substance, it is necessary to know its mechanism.

Major products of ammoxidation of aromatic compounds, having methyl groups at ortho-position, are both dinitrile and imide [10]-[12], which are used in production of phthalocyanine pigments and dyes, photosensitizers of near IR spectrum for photodynamic cancer therapy [8] [9], laser dyes, thermally stable polymers, medications, chemical means of plant protection and other fields of organic synthesis.

\section{Methods and Apparatus}

Kinetic measurements of 4-phenyl-o-xylene conversion and chromatographic separation of catalyzate components, and a quantitative calculation of their content were carried out in accordance with the earlier developed methods [1]. Kinetic measurements were performed in a setup with a vibrating fluidized-bed, gradientless flow reactor of $20-\mathrm{cm}^{3}$ capacity made from 12Kh18N10T steel (Figure 2). Feed system of the reagents. Dosage of gaseous components of the initial reaction mixture, containing oxygen, ammonia and nitrogen (as gas-diluent), feed from cylinders, was being carried out by means of stopcocks $\{1\}$ and a fine adjustment valve $\{5\}$. Gases cleaning and drying were being carried out in the gas columns $\{3\}$. Measurement of gases consumption was being performed by rheometers $\{4\}$ with calibrated capillaries, and pressure in the system was being maintained constant by manostats $\{2\}$. 4-Phenyl-o-tolunitrile in liquid state by means of dispenser of syringe type $\{9\}$ and gaseous reagents through the mixer $\{6\}$ were being fed into the evaporator $\{7\}$, heated by oven $\{8\}$. The reaction assembly included a reactor $\{10\}$ equipped with a thermowell, a grid (the same brand as the reactor), pre- 


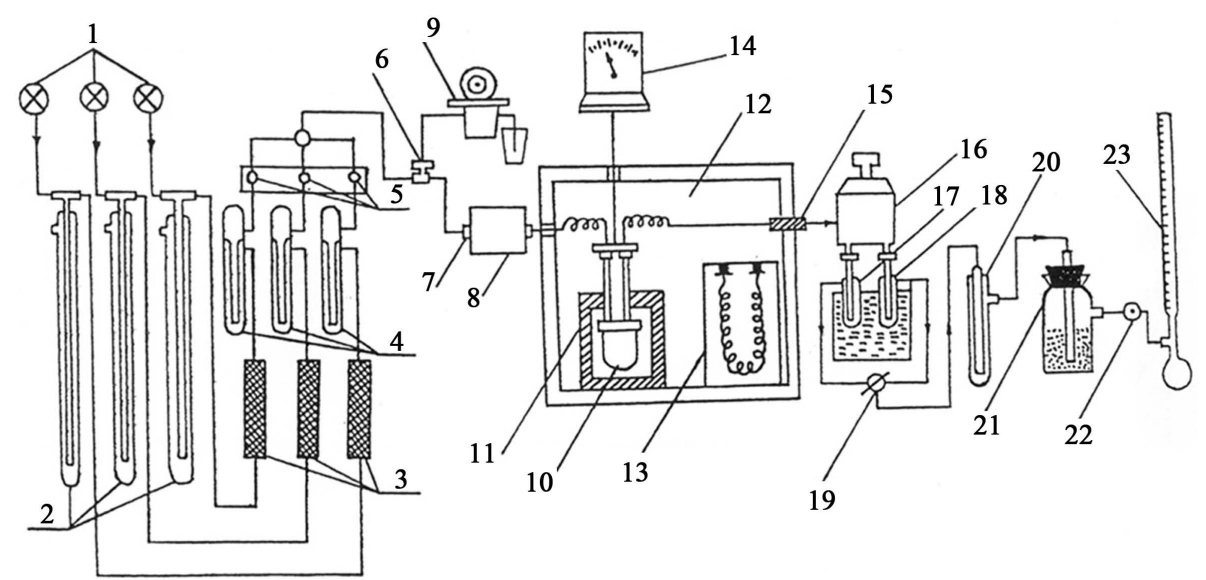

Figure 2. Scheme of gradientless installation with vibrating liquefied bed of catalyst.

venting entrainment of catalyst dust, as well as a vibrator $\{14\}$ with the oscillation frequency of $50 \mathrm{~Hz}$ and an adjustable amplitude. Temperature in the reaction zone was being measured using a sliding thermocouple and recorded by electronic potentiometer KSP-4M. Temperature of block furnace $\{11\}$ and the reactor were being controlled by a potentiometer KVP I-503 with accuracy to $\pm 2^{\circ}$. The furnace with a reactor was being placed in a thermostat $\{12\}$. Temperature in the thermostat was being maintained at $570-580 \mathrm{~K}$ by electrical spirals $\{13$, $15\}$ sufficient to prevent condensation of the reaction products. A system for collecting the reaction products included a heated switch $\{16\}$, with solvent trap of reaction products $\{17,18\}$, the three-way cock $\{19\}$, a trap filled with sulfuric acid solution for quantitative recovery of unreacted ammonia $\{20\}$, a desiccant $\{21\}$, a gas sampler $\{22\}$, foam flow meter of flow rate $\{23\}$.The described scheme provides a material balance for all substances-reaction participants.

The products absorbed by 1,4-dioxane were determined on a Chrome-5 chromatograph equipped with an FID and a column of $1.2 \mathrm{~m}$ length. The column packing was Chromaton N-AW (0.2 - $0.25 \mathrm{~mm})$ coated with a mixed stationary phase of Apiezon L (21\%) and PEG 40000 (0.5\%) or with Polisorb-1 (0.25 - 0.5 mm) alone. Carbon dioxide was determined on LKhM-8MD chromatograph with triethylene glycol butyrate supported on INZ-600 (calcined diatomaceous earth) as the stationary phase. Separation of $\mathrm{O}_{2}$ and $\mathrm{N}_{2}$ was carried out on the same chromatoraph using a parallel column packed with $\mathrm{NaX}$.

\section{Analysis of Experimental Products}

In products of the reaction of 4-phenyl-o-xylene (I) ammoxidation on $\mathrm{V}$-Sb-Bi- $\mathrm{Zr} / \gamma-\mathrm{Al}_{2} \mathrm{O}_{3}$-oxide catalyst 4phenyl-o-tolunitrile (II), 4-phenylphthalonitrile (III), 4-phenylpthalimide (IV), 4-phenylbenzonitrile (V), carbon dioxide, unreacted I, oxygen and the diluent gas-nitrogen were determined by gas chromatography. The reaction gases were successively passed through a 1,4-dioxane-filled trap for absorption of nitriles, and IV and sulfuric acid-filled trap for absorption of ammonia. The concentration of ammonia at the reactor outlet was determined by titration of unreacted sulfuric acid from the second trap. The carrier-gas (nitrogen) flow rate was $80 \mathrm{~mL} / \mathrm{min}$. The sample injection temperature was $353 \mathrm{~K}$, and the temperature programming rate was $20 \mathrm{~K} / \mathrm{min}$.

\section{Results and Discussion}

In previous papers [2] [3] it has been shown, that at 4-phenyl-o-xylene ammoxidation on the oxide catalyst $\mathrm{V}-\mathrm{Sb}-\mathrm{Bi}-\mathrm{Zr} / \gamma-\mathrm{Al}_{2} \mathrm{O}_{3}$ due to the electronic factor of a phenyl group para-methyl groups are activated first, then meta-methyl groups are activated second with respect to substituent in an aromatic nucleus. By the way, the phenyl group is related to substituent of the third kind [13], which may show both electron-donating and electron-withdrawing properties and, taking into account lack of a significant role of conjugation, i.e. electron-donating property of the phenyl group, due to the fact that resonance constants of phenyl and methyl groups, located at the para-position, are not significantly different [14] [15], therefore should be noted that the phenyl group in 4-phenyl-o-xylene molecule reveals the electron-withdrawing character. As the phenyl group in 4phenyl-o-xylene molecule does not affect on activation of meta-methyl group [16], then on the basis of the elec- 
tron-withdrawing property of phenyl group and a positive inductive $(+\mathrm{J})$ effect of para-methyl group it can be said, that both influence on activation of para-methyl group in regard to phenyl substituent. Thus, as a result of activation first intermediate 4-phenyl-o-tolunitrile and then 4-phenylphthalonitrile are formed [1] [2].

For unsubstituted o-xylene it does not matter which of two methyl groups is activated first in an aromatic nucleus. Therefore, as a result of activation of one from two methyl groups only o-tolunitrile is formed, which in its turn, due to activation of the second methyl group under the conditions of oxidative ammonolysis [17] [18] forms dinitrile. On the other hand, study of ammoxidation processes of 4-substituted o-xylene [1] [2] [7] [19][23] on the modified V-Sb-Bi $/ \gamma-\mathrm{Al}_{2} \mathrm{O}_{3}$ catalysts, including $\mathrm{V}$-Sb-Bi- $\mathrm{Zr} / \gamma-\mathrm{Al}_{2} \mathrm{O}_{3}$-oxide contact, shows, that introduction of the phenyl group, or bromine atom into the aromatic nucleus of o-xylene negatively affects on its reactivity, where the phenyl substituent exerts the less negative influence [15]. In modern organic chemistry summative influence of substituents on the reaction center can be subdivided into induction and resonance (conjugation), i.e. the electronic and steric constituents, from which upon adsorption of 4-phenyl-o-xylene by the methyl group the steric factor [15] and upon activation (chemisorption) electronic factor [3] play a noticeable role.

During the primary activation of alkyl aromatic compounds with the metal oxide catalyst under the ammoxidation conditions lateral C-H bonds, being in $\alpha$-position to an aromatic nucleus, are broken [24]. Activation mechanism under the action of primary center-of nucleophilic oxygen ion is shown in Figure 3.

As seen, efficiency of heterolytic dissociation of the C-H bond in the methyl group is ensured, first of all, by interaction of nucleophilic oxygen $\left(\mathrm{O}^{2-}\right)$ with the protonated hydrogen. The heterolytic breakage of $\mathrm{C}-\mathrm{H}$ bonds occurs also at activation of the second methyl group of 4-phenyl-o-xylene, since 4-phenilphthalonitrile is formed on V-Sb-Bi- $\mathrm{Zr} / \gamma-\mathrm{Al}_{2} \mathrm{O}_{3}$-oxide catalyst mainly from 4-phenyl-o-tolunitrile. Thus, the primary interaction of 4phenyl-o-xylene with the contact surface has an acid-base character, i.e. stage 1 (Figure 3) proceeds without changing an oxidation state of the metal $\mathrm{M}^{\mathrm{n}+}$ and is accompanied by separation of a proton from the substrate molecule (CH-acid) on nucleophilic catalyst center forming a surface compound of anionic type [3] [24]. For the oxidative reactions, mechanism of which comprises the acid-base stages, use of notions about the combined influence of redox and acid-base characteristics of the surface on the catalytic properties of substances is more productive [25]. Ammoxidation processes of toluene and its homologs, the primary interaction of which with the oxide catalyst can show the acid-base character [24] should be related to these reactions.

The purpose of the present article is to discuss a formation mechanism of the products of 4-phenyl-o-xylene ammoxidation, consistent with the observed kinetic regularities.

It is important to add, that as distinct from easiness of study of ammoxidation mechanism of olefinic and paraffinic hydrocarbons series [26] [27], methodological difficulties, caused by comparatively high boiling and sublimation temperatures of initial substances and reaction products, highly detain conducting of detailed researches of ammoxidation mechanism of alkyl aromatic compounds [24]. The mechanism even for the simplest and sufficiently well-studied processes of ammoxidation remains still unexplained. An even greater difficulty is a study of the mechanism, as a result of which not only one but also two nitrile groups are formed, and imide group as well.

Earlier discussed by us, the formation mechanism of the products of o-xylene and p-xylene ammoxidation, consistent with the observed kinetic regularities, showed that in both cases dependence of the consumption rate of substrates allowed supposing their dissociative adsorption.

4-Phenyl-o-tolunitrile (II), 4-phenylphthalonitrile (III), 4-phenylphthalimide (IV), 4-phenylbenzonitrile (V) and $\mathrm{CO}_{2}$ are formed at vapor phase ammoxidation of 4-phenyl-o-xylene (I) in accordance with the Figure 1. Analysis of the experimental data showed, that formation and consumption rates of the basic components of the reaction of 4-phenyl-o-xylene ammoxidation on $\mathrm{V}-\mathrm{Sb}-\mathrm{Bi}-\mathrm{Zr} / \gamma-\mathrm{Al}_{2} \mathrm{O}_{3}$-oxide catalyst in a range of the partial pressures of oxygen and ammonia (whose measuring unit is $\mathrm{kPa}$ ), exceeding their minimum values, are described by the Equations (1)-(7).
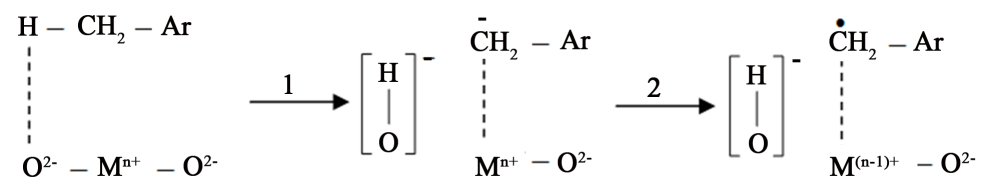

Figure 3. The mechanism of activation of the substrate with the catalyst under ammoxidation. 


$$
\begin{gathered}
W_{1}=\kappa_{1} \sqrt{P_{I}} \\
W_{2}=\kappa_{2} \sqrt{P_{I I}} \\
W_{3}=\kappa_{3} P_{I I I} \cdot P_{\mathrm{H}_{2} \mathrm{O}} / P_{\mathrm{NH}_{3}} \\
W_{4}=\kappa_{4} P_{I V} / P_{\mathrm{H}_{2} \mathrm{O}} \\
W_{5}=\kappa_{5} \\
W_{6}=\kappa_{6} P_{I I} / 1+a P_{I} \\
W_{9}=\kappa_{9} \sqrt{P_{I}}
\end{gathered}
$$

Here $\kappa_{i}$ is a constant of the route rate (Figure 1).

Taking into account the observed dependence of the formation of the reaction products on the ratio of $\mathrm{O}_{2}$ and $\mathrm{NH}_{3}$ concentrations at values $P_{\mathrm{NH}_{3}}$, lesser of some value, denoted as $\left(P_{\mathrm{NH}_{3}}\right)_{\min }$ [1], the rates of conversion of 4-phenyl-o-xylene into 4-phenyl-o-tolunitrile and 4-phenyl-o-tolunitrile into 4-phenylphthalonitrile are expressed by the Equations (8) and (9), respectively.

$$
\begin{gathered}
W_{1}=\kappa_{1} \sqrt{P_{I}} P_{\mathrm{NH}_{3}} / P_{\mathrm{NH}_{3}}+b P_{\mathrm{O}_{2}} \\
W_{2}=\kappa_{2} \sqrt{P_{I I}} P_{\mathrm{NH}_{3}} / P_{\mathrm{NH}_{3}}+b P_{\mathrm{O}_{2}}
\end{gathered}
$$

In the indicated range of ammonia concentrations the routes 7 and 8 are added according to the Figure 1, the rates of which are described by the Equations (10) and (11).

$$
\begin{gathered}
W_{7}=\kappa_{1} \sqrt{P_{I}} b P_{\mathrm{O}_{2}} \beta / P_{\mathrm{NH}_{3}}+b P_{\mathrm{O}_{2}} \\
W_{8}=\kappa_{1} \sqrt{P_{I}} b P_{\mathrm{O}_{2}}(1-\beta) / P_{\mathrm{NH}_{3}}+b P_{\mathrm{O}_{2}}
\end{gathered}
$$

Here $\beta$ is a share of 4-phenyl-o-xylene, which at small concentrations of ammonia is converted to 4-phenylphthalimide; $b$ is a constant reflecting ratio of the adsorption equilibrium constants of $\mathrm{O}_{2}$ and $\mathrm{NH}_{3}$.

$$
W_{\text {sum }}=W_{1}+W_{7}+W_{8}+W_{9}=\left(\kappa_{1}+\kappa_{9}\right) \sqrt{P_{I}}
$$

In accordance with Figure $1, W_{\text {sum }}$ is independent on $\mathrm{NH}_{3}$ concentration and obeys the half-order equation on 4-phenyl-o-xylene. Such dependence allows assuming a dissociative adsorption of 4-phenyl-o-xylene at centers, which at $P_{\mathrm{O}_{2}}>\left(P_{\mathrm{O}_{2}}\right)_{\text {min }}$ is completely covered with oxygen. At the same time the adsorbed 4-phenyl-o-xylene fragment with probability $\kappa_{9} / \kappa_{1}+\kappa_{9}$ along the route 9 is oxidized to $\mathrm{CO}_{2}$ and $\mathrm{H}_{2} \mathrm{O}$, with probability $\kappa_{1} / \kappa_{1}+\kappa_{9}$ leads to the formation of 4-phenyl-o-tolunitrile, and at small values of $P_{\mathrm{NH}_{3}}$ also produces 4-phenylphthalimide, $\mathrm{CO}_{2}$ and $\mathrm{H}_{2} \mathrm{O}$. Correlation of the formation rates of 4-phenyl-o-tolunitrile on the route $1\left(W_{1}\right)$ and other products of the reaction on the routes 7 and $8\left(W_{7}+W_{8}\right)$ depends on the ratio of $P_{\mathrm{NH}_{3}} / P_{\mathrm{O}_{2}}$. This together with independence of the conversion rate of 4-phenyl-o-xylene on $P_{\mathrm{NH}_{3}}$ gives a reason to suggest, that $\mathrm{NH}_{3}$ is adsorbed on other centers, than 4-phenyl-o-xylene, besides in this adsorption it competes with oxygen, completely displacing it at the high values of $P_{\mathrm{NH}_{3}}$. Obviously, these centers (Z) have less adsorption heat of oxygen than the adsorption centers of 4-phenyl-o-xylene (Y).

Taking into consideration the foregoing, sequence of the steps leading to adsorption of 4-phenyl-o-xylene and its complete oxidation on the route 9 can be represented in the following way:

1) $2 \mathrm{YO}+\mathrm{CH}_{3} \mathrm{PhC}_{6} \mathrm{H}_{3} \mathrm{CH}_{3} \rightleftarrows \mathrm{YOCHPhC}_{6} \mathrm{H}_{3} \mathrm{CH}_{3}+\mathrm{YOH}_{2}$

2) $\mathrm{YOCHPhC}_{6} \mathrm{H}_{3} \mathrm{CH}_{3}+\mathrm{YO} \rightarrow \mathrm{YO}_{2} \mathrm{CHPhC}_{6} \mathrm{H}_{3} \mathrm{CH}_{3}+\mathrm{Y}$

3) $\mathrm{YOCHPhC}_{6} \mathrm{H}_{3} \mathrm{CH}_{3}+2 \mathrm{YO} \rightarrow \mathrm{YOCHPhC}_{6} \mathrm{H}_{3} \mathrm{CHOY}+\mathrm{YOH}_{2}$

4') $\mathrm{YOCHC}_{6} \mathrm{H}_{5} \mathrm{C}_{6} \mathrm{H}_{3} \mathrm{CHOY}+15.5 \mathrm{O}_{2} \rightarrow 14 \mathrm{CO}_{2}+5 \mathrm{H}_{2} \mathrm{O}+2 \mathrm{Y}$

5) $\mathrm{YOH}_{2} \rightarrow \mathrm{Y}+\mathrm{H}_{2} \mathrm{O}$

6') $2 \mathrm{Y}+\mathrm{O}_{2} \rightarrow 2 \mathrm{YO}$

Here, step 1) is the equilibrium stage, the stages with dashes are instant [28], all other stages are slow, and 
$\mathrm{C}_{6} \mathrm{H}_{5}=\mathrm{Ph}$.

Equilibriumly adsorbed on centers $\mathrm{ZO}_{2}$ and $\mathrm{NH}_{3}$ completely cover their.

7) $\mathrm{Z}+\mathrm{O}_{2} \rightleftarrows \mathrm{ZO}_{2}$

8) $\mathrm{Z}+\mathrm{NH}_{3} \rightleftarrows \mathrm{ZNH}_{3}$

Hence:

$$
\left[\mathrm{ZO}_{2}\right]+\left[\mathrm{ZNH}_{3}\right]=1
$$

Then $\mathrm{O}_{2}$ and $\mathrm{NH}_{3}$ covering can be calculated as follows.

$$
\begin{gathered}
{\left[\mathrm{ZO}_{2}\right]=K_{7} P_{\mathrm{O}_{2}} / K_{8} P_{\mathrm{NH}_{3}}+K_{7} P_{\mathrm{O}_{2}}=K_{7} / K_{8} P_{\mathrm{O}_{2}} / P_{\mathrm{NH}_{3}}+K_{7} / K_{8} P_{\mathrm{O}_{2}}} \\
{\left[\mathrm{ZNH}_{3}\right]=K_{8} P_{\mathrm{O}_{2}} / K_{8} P_{\mathrm{NH}_{3}}+K_{7} P_{\mathrm{O}_{2}}=P_{\mathrm{NH}_{3}} / P_{\mathrm{NH}_{3}}+K_{7} / K_{8} P_{\mathrm{O}_{2}}}
\end{gathered}
$$

Here, $K_{i}$ is an equilibrium constant of the reaction stage.

If $\mathrm{YO}_{2} \mathrm{CHPhC}_{6} \mathrm{H}_{3} \mathrm{CH}_{3}$ interacts with $\mathrm{ZNH}_{3}$, then 4-phenyl-o-tolunitrile is formed, in the case of interaction with $\mathrm{ZO}_{2}$ either 4-phenylphthalimide or $\mathrm{CO}_{2}$ and $\mathrm{H}_{2} \mathrm{O}$ are formed on the routes 7 and 8 (Figure 1).

9') $\mathrm{YO}_{2} \mathrm{CHPhC}_{6} \mathrm{H}_{3} \mathrm{CH}_{3}+\mathrm{ZNH}_{3} \rightarrow \mathrm{CH}_{3} \mathrm{C}_{6} \mathrm{H}_{3} \mathrm{PhCN}+\mathrm{Y}+\mathrm{Z}+2 \mathrm{H}_{2} \mathrm{O}$

10') $\mathrm{YO}_{2} \mathrm{CHPhC}_{6} \mathrm{H}_{3} \mathrm{CH}_{3}+\mathrm{ZO}_{2} \rightarrow \mathrm{PhC}_{6} \mathrm{H}_{3}\left\langle\begin{array}{l}\mathrm{CO} \\ \mathrm{CO}\end{array}\right\rangle \mathrm{Y}+\mathrm{Z}+2 \mathrm{H}_{2} \mathrm{O}$

$\left.11^{\prime}\right)$

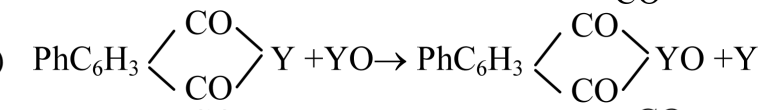

12') $\mathrm{PhC}_{6} \mathrm{H}_{3}\left\langle\begin{array}{l}\mathrm{CO} \\ \mathrm{CO}\end{array}\right\rangle \mathrm{YO}+\mathrm{NH}_{3} \rightarrow \mathrm{PhC}_{6} \mathrm{H}_{3}\left\langle\begin{array}{l}\mathrm{CO} \\ \mathrm{CO}\end{array}\right\rangle \mathrm{NH}+\mathrm{H}_{2} \mathrm{O}+\mathrm{Y}$

13') $\mathrm{PhC}_{6} \mathrm{H}_{3}\left\langle\begin{array}{l}\mathrm{CO} \\ \mathrm{CO}\end{array}\right\rangle \mathrm{Y}+2 \mathrm{YO} \rightarrow \mathrm{PhC}_{6} \mathrm{H}_{3}\left\langle\begin{array}{l}\mathrm{C}-\mathrm{O}-\mathrm{O}-\mathrm{Y} \\ \mathrm{I}\end{array}\right.$

14') $\mathrm{C}_{6} \mathrm{H}_{5} \mathrm{C}_{6} \mathrm{H}_{3}\left\langle\underset{\mathrm{C}-\mathrm{O}-\mathrm{O}-\mathrm{Y}-\mathrm{O}-\mathrm{O}-\mathrm{Y}}{\mathrm{Y}}+14 \mathrm{O}_{2} \rightarrow 14 \mathrm{CO}_{2}+4 \mathrm{H}_{2} \mathrm{O}+3 \mathrm{Y}\right.$

Covering of $\mathrm{Y}$ centers by the fragments of organic origin is little.

If consumption rate of $\mathrm{YOCHPhC}_{6} \mathrm{H}_{3} \mathrm{CH}_{3}$ in the stages 2) and 3) is approximately equals to consumption rate of $\mathrm{YOH}_{2}$ in the stage 5), then their concentrations are also equal with each other, i.e. [YOCHPhC $\left.{ }_{6} \mathrm{H}_{3} \mathrm{CH}_{3}\right] \approx$ $\left[\mathrm{YOH}_{2}\right]$.

Then, from the equilibrium stage 1 ) and condition of full covering of Y centers by oxygen ([YO] $\approx 1)$ we obtain the expressions (16) and (17).

$$
\begin{aligned}
& K_{1}=\left[\mathrm{YOCHPhC}_{6} \mathrm{H}_{3} \mathrm{CH}_{3}\right]^{2} / P_{I} \\
& {\left[\mathrm{YOCHPhC}_{6} \mathrm{H}_{3} \mathrm{CH}_{3}\right]=\sqrt{K_{1} P_{I}}}
\end{aligned}
$$

The consumption rate of 4-phenyl-o-xylene on the route 9, taking into account defining of this direction slow stage 3 ) at $[\mathrm{YO}] \approx 1$, is determined by the Equation (18), and on the routes 1,7 and 8 , taking into account defining of the direction slow stage 2 ) at $[\mathrm{YO}] \approx 1$ by the Equation (19).

$$
\begin{gathered}
W_{9}=k_{3}\left[\mathrm{YOCHPhC}_{6} \mathrm{H}_{3} \mathrm{CH}_{3}\right]=k_{3} \sqrt{K_{1} P_{I}} \\
W_{1}+W_{7}+W_{8}=k_{2}\left[\mathrm{YOCHPhC}_{6} \mathrm{H}_{3} \mathrm{CH}_{3}\right]=k_{2} \sqrt{K_{1} P_{I}} \\
\kappa_{1}=k_{2} \sqrt{K_{1}}, \quad \kappa_{9}=k_{3} \sqrt{K_{1}}
\end{gathered}
$$

Here, $k_{i}$ is a rate constant of the reaction stage.

The values $W_{1}$ and $\left[W_{7}+W_{8}\right]$, taking into account coverings of $\mathrm{NH}_{3}$ and $\mathrm{O}_{2}$, which determine the routes 1 and $[7+8]$ are found by the Equations (21) and (22).

$$
W_{1}=k_{2} \sqrt{K_{1} P_{I}} P_{\mathrm{NH}_{3}} / P_{\mathrm{NH}_{3}}+K_{7} / K_{8} P_{\mathrm{O}_{2}}
$$




$$
\begin{gathered}
W_{7}+W_{8}=k_{2} \sqrt{K_{1} P_{I}} K_{7} / K_{8} P_{\mathrm{O}_{2}} / P_{\mathrm{NH}_{3}}+K_{7} / K_{8} P_{\mathrm{O}_{2}} \\
b=K_{7} / K_{8}
\end{gathered}
$$

In turn, the rates ratio of the routes 7 and 8 is defined by relation of the constants of the stages $\left.11^{\prime}\right)$ and $\left.13^{\prime}\right)$.

$$
\begin{gathered}
W_{7} / W_{8}=\beta / 1-\beta=k_{11^{\prime}} / k_{13^{\prime}} \\
\beta=k_{11^{\prime}} / k_{11^{\prime}}+k_{13^{\prime}}
\end{gathered}
$$

On the Y centers, analogously to adsorption of 4-phenyl-o-xylene, 4-phenyl-o-tolunitrile is dissociatively adsorbed.

15) $2 \mathrm{YO}+\mathrm{CH}_{3} \mathrm{PhC}_{6} \mathrm{H}_{3} \mathrm{CN} \rightleftarrows \mathrm{YOCHPhC}_{6} \mathrm{H}_{3} \mathrm{CN}+\mathrm{YOH}_{2}$

16) $\mathrm{YOCHPhC}_{6} \mathrm{H}_{3} \mathrm{CN}+\mathrm{YO} \rightarrow \mathrm{YO}_{2} \mathrm{CHPhC}_{6} \mathrm{H}_{3} \mathrm{CN}+\mathrm{Y}$

17') $\mathrm{YO}_{2} \mathrm{CHPhC}_{6} \mathrm{H}_{3} \mathrm{CN}+\mathrm{ZNH}_{3} \rightarrow \mathrm{PhC}_{6} \mathrm{H}_{3}(\mathrm{CN})_{2}+\mathrm{Y}+\mathrm{Z}$

Since the formation rates of $\mathrm{YOCHPhC}_{6} \mathrm{H}_{3} \mathrm{CN}$ and $\mathrm{YOH}_{2}$ at the stage 15) are the same, then $\left[\mathrm{YOCHPhC}_{6} \mathrm{H}_{3} \mathrm{CN}\right]=\left[\mathrm{YOH}_{2}\right]$.

Therefore, from the equilibrium of the stage 15) and the conditions of full coverage of the Y centers by oxygen $([\mathrm{YO}] \approx 1)$ follows

$$
K_{15}=\left[\mathrm{YOCHPhC}_{6} \mathrm{H}_{3} \mathrm{CN}\right]^{2} / P_{I I}
$$

hence

$$
\left[\mathrm{YOCHPhC}_{6} \mathrm{H}_{3} \mathrm{CN}\right]=\sqrt{K_{15} P_{I I}}
$$

Then, the consumption rate of 4-phenyl-o-tolunitrile on the route 2, taking into account defining of this direction slow stage 16 ) at $[\mathrm{YO}] \approx 1$, is determined by the Equation (28).

$$
W_{2}=k_{16}\left[\mathrm{YOCHPhC}_{6} \mathrm{H}_{3} \mathrm{CN}\right]=k_{16} \sqrt{K_{15} P_{I I}}
$$

Taking into consideration $\mathrm{NH}_{3}$ covering, which determines the route 2, the reaction rate is determined by the Equation (29).

$$
\begin{gathered}
W_{2}=k_{16} \sqrt{K_{15} P_{I I}} P_{\mathrm{NH}_{3}} / P_{\mathrm{NH}_{3}}+b P_{\mathrm{O}_{2}} \\
\kappa_{2}=k_{16} \sqrt{K_{15}}
\end{gathered}
$$

A character of kinetic dependencies of hydrolysis of 4-phenylphthalonitrile and reverse reaction of 4-phenylphthalimide ammonolysis on water and ammonia concentrations shows, that these reactions occur on the catalytic centers of different nature. Ammonia on them competes with water, and ammonia covering is much more than covering by adsorbed water and close to 1 .

18) $\mathrm{X}+\mathrm{H}_{2} \mathrm{O} \rightleftarrows \mathrm{X}\left(\mathrm{H}_{2} \mathrm{O}\right)$

19) $\mathrm{X}+\mathrm{NH}_{3} \rightleftarrows \mathrm{X}\left(\mathrm{NH}_{3}\right)$

20) $\mathrm{X}\left(\mathrm{H}_{2} \mathrm{O}\right)+\mathrm{PhC}_{6} \mathrm{H}_{3}(\mathrm{CN})_{2} \rightleftarrows \mathrm{X}\left(\mathrm{PhC}_{6} \mathrm{H}_{3} \underset{\mathrm{CN}}{\nearrow}{ }^{\mathrm{CO}-\mathrm{NH}_{2}}\right)$

21) $\left.\mathrm{X}_{\left(\mathrm{PhC}_{6} \mathrm{H}_{3}\right.} \succ_{\mathrm{CN}}^{\mathrm{CO}-\mathrm{NH}_{2}}\right)+\mathrm{H}_{2} \mathrm{O} \rightleftarrows \mathrm{PhC}_{6} \mathrm{H}_{3}\left\langle{ }_{\mathrm{CO}}^{\mathrm{CO}}\right\rangle \mathrm{NH}+\mathrm{X}\left(\mathrm{NH}_{3}\right)$

Here, the stages 18), 19) and 21) are equilibrium stages; stage 20) is reversible, but not the equilibrium.

Covering with adsorbed water is calculated by the Equation (31).

$$
\left[\mathrm{X}\left(\mathrm{H}_{2} \mathrm{O}\right)\right]=K_{18} P_{\mathrm{H}_{2} \mathrm{O}} / K_{19} P_{\mathrm{NH}_{3}}
$$

Then, the reaction rate on the route 3 in the forward direction, taking into account defining of the direction stage 20), is determined by the Equation (32).

$$
W_{3}=k_{20} P_{I I I}\left[\mathrm{X}\left(\mathrm{H}_{2} \mathrm{O}\right)\right]=k_{20} P_{I I I} K_{18} P_{\mathrm{H}_{2} \mathrm{O}} / K_{19} P_{\mathrm{NH}_{3}}
$$




$$
\kappa_{3}=k_{20} K_{18} / K_{19}
$$

The equilibrium constant of the stage 21 ), taking into account $\left[\mathrm{X}\left(\mathrm{NH}_{3}\right)\right] \approx 1$ is equal to:

$$
K_{21}=P_{I V} / P_{\mathrm{H}_{2} \mathrm{O}}\left[\mathrm{X}\left(\mathrm{PhC}_{6} \mathrm{H}_{3}\left\langle{ }_{\mathrm{CN}}^{\mathrm{CO}-\mathrm{NH}_{2}}\right)\right]\right.
$$

Hence, covering with the intermediate compound:

$$
\left[\mathrm{X}\left(\mathrm{PhC}_{6} \mathrm{H}_{3} \succ_{\mathrm{CN}}{ }_{\mathrm{CO}-\mathrm{NH}_{2}}\right)\right]=P_{I V} / K_{21} P_{\mathrm{H}_{2} \mathrm{O}}
$$

Then, the reaction rate on the route 4 of the reverse direction of 4-phenylphthalimide ammonolysis, taking into account defining stage 20), is equal to:

$$
W_{4}=k_{-20}\left[\mathrm{X}\left(\mathrm{PhC}_{6} \mathrm{H}_{3} \nearrow_{\mathrm{CN}}^{\mathrm{CO}-\mathrm{NH}_{2}}\right)\right]=k_{-20} P_{I V} / K_{21} P_{\mathrm{H}_{2} \mathrm{O}}
$$

Consequently,

$$
\kappa_{4}=k_{-20} / K_{21}
$$

At equilibrium,

$$
W_{3}=W_{4}
$$

Then,

$$
k_{20} K_{18} P_{I I I} P_{\mathrm{H}_{2} \mathrm{O}} / K_{19} P_{\mathrm{NH}_{3}}=k_{-20} P_{I V} / K_{21} P_{\mathrm{H}_{2} \mathrm{O}}
$$

and equilibrium constant of the hydrolysis reaction of 4-phenylphthalonitrile may be expressed in the following way (40).

$$
k_{20} K_{18} K_{21} / K_{19} k_{-20}=P_{I V} P_{\mathrm{NH}_{3}} / P_{I I I} P_{\mathrm{H}_{2} \mathrm{O}}^{2}=K_{p}=K_{3} / K_{4}
$$

If to judge on the observed kinetic regularities [1] [2], then formation of 4-phenylbenzonitrile both from 4phenylphthalimide and from 4-phenyl-o-tolunitrile occurs on other centers than ammoxidation. Existence of such centers on the surface of the multicomponent catalyst is quite possible. Therefore, a character of the kinetic dependences of 4-phenylphthalimide decarboxylation shows, that this reaction takes place on of catalytic centers $(\Omega)$, covered with imide.

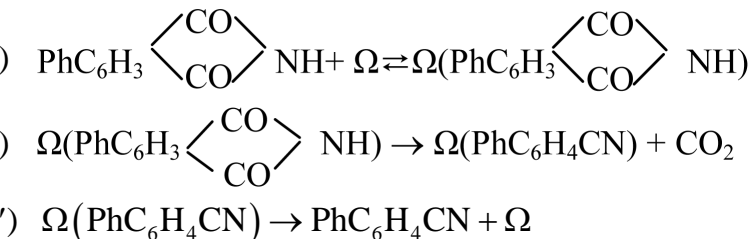

The consumption rate of 4-phenylphthalimide on the route 5 , taking into account defining of the direction slow stage 23) at covering with imide, closed to 1 ,

$$
W_{5}=k_{23}
$$

Consequently,

$$
\kappa_{5}=k_{23}
$$

Formation of 4-phenylbenzonitrile at the oxidative destruction (oxidative demethylation) of 4-phenyl-o-tolunitrile is impeded by 4-phenyl-o-xylene, and therefore, 4-phenyl-o-xylene and 4-phenyl-o-tolunitrile equilibriumly adsorbing on $\Lambda$ centers cover them.

25) $\Lambda+\mathrm{CH}_{3} \mathrm{PhC}_{6} \mathrm{H}_{3} \mathrm{CH}_{3} \rightleftarrows \Lambda\left(\mathrm{CH}_{3} \mathrm{PhC}_{6} \mathrm{H}_{3} \mathrm{CH}_{3}\right)$

26) $\Lambda+\mathrm{CH}_{3} \mathrm{PhC}_{6} \mathrm{H}_{3} \mathrm{CN} \rightleftarrows \Lambda\left(\mathrm{CH}_{3} \mathrm{PhC}_{6} \mathrm{H}_{3} \mathrm{CN}\right)$

Then coverings of 4-phenyl-o-xylene and 4-phenyl-o-tolunitrile are determined by the equations $(43,44)$. 


$$
\begin{gathered}
{\left[\Lambda\left(\mathrm{CH}_{3} \mathrm{PhC}_{6} \mathrm{H}_{3} \mathrm{CH}_{3}\right)\right]=K_{25} P_{I} / K_{25} P_{I}+K_{26} P_{I I}=K_{25} / K_{26} P_{I} / K_{25} / K_{26} P_{I}+P_{I I}} \\
{\left[\Lambda\left(\mathrm{CH}_{3} \mathrm{PhC}_{6} \mathrm{H}_{3} \mathrm{CN}\right)\right]=K_{26} P_{I I} / K_{26} P_{I I}+K_{25} P_{I}=P_{I I} / P_{I I}+K_{25} / K_{26} P_{I}}
\end{gathered}
$$

Sequence of the stages of 4-phenyl-o-tolunitrile oxidative destruction on the route 6 can be represented as follows.

27) $3 \Lambda+1.5 \mathrm{O}_{2} \rightarrow 3 \Lambda \mathrm{O}$

28) $\Lambda\left(\mathrm{CH}_{3} \mathrm{PhC}_{6} \mathrm{H}_{3} \mathrm{CN}\right)+2 \Lambda \mathrm{O} \rightarrow \Lambda\left(\mathrm{HOCPhC}_{6} \mathrm{H}_{3} \mathrm{CN}\right)+\Lambda \mathrm{OH}_{2}+\Lambda$

29') $\Lambda\left(\mathrm{HOCPhC}_{6} \mathrm{H}_{3} \mathrm{CN}\right)+\Lambda \mathrm{O} \rightarrow \Lambda\left(\mathrm{HOOCPhC}_{6} \mathrm{H}_{3} \mathrm{CN}\right)+\Lambda$

30') $\Lambda\left(\mathrm{HOOCPhC}_{6} \mathrm{H}_{3} \mathrm{CN}\right) \rightarrow \Lambda\left(\mathrm{PhC}_{6} \mathrm{H}_{4} \mathrm{CN}\right)+\mathrm{CO}_{2}$

31') $\Lambda\left(\mathrm{PhC}_{6} \mathrm{H}_{4} \mathrm{CN}\right) \rightarrow \mathrm{PhC}_{6} \mathrm{H}_{4} \mathrm{CN}+\Lambda$

32) $\Lambda \mathrm{OH}_{2} \rightarrow \Lambda+\mathrm{H}_{2} \mathrm{O}$

From the foregoing follows, that

$$
\left[\Lambda\left(\mathrm{CH}_{3} \mathrm{PhC}_{6} \mathrm{H}_{3} \mathrm{CH}_{3}\right)\right]+\left[\Lambda\left(\mathrm{CH}_{3} \mathrm{PhC}_{6} \mathrm{H}_{3} \mathrm{CN}\right)\right] \approx 1
$$

Taking into consideration this, and because of the relatively low yields of 4-phenylbenzonitrile even on the routes 5 and 6 (Figure 1) may assume, that $\Lambda$ centers covering with the fragments of inorganic origin are very small (46).

$$
\left[\Lambda\left(\mathrm{CH}_{3} \mathrm{PhC}_{6} \mathrm{H}_{3} \mathrm{CH}_{3}\right)\right]+\left[\Lambda\left(\mathrm{CH}_{3} \mathrm{PhC}_{6} \mathrm{H}_{3} \mathrm{CN}\right)\right] \gg[\Lambda \mathrm{O}]
$$

From the stage 26) for $\left[\Lambda\left(\mathrm{CH}_{3} \mathrm{PhC}_{6} \mathrm{H}_{3} \mathrm{CN}\right)\right]$, taking into account sum of the centers numbers, equal to unity, we obtain the following expressions (47) and (48).

$$
\begin{gathered}
K_{26}=\left[\Lambda\left(\mathrm{CH}_{3} \mathrm{PhC}_{6} \mathrm{H}_{3} \mathrm{CN}\right)\right] / P_{I I} \\
{\left[\Lambda\left(\mathrm{CH}_{3} \mathrm{PhC}_{6} \mathrm{H}_{3} \mathrm{CN}\right)\right]=K_{26} P_{I I}}
\end{gathered}
$$

Then, the consumption rate of $\Lambda\left(\mathrm{CH}_{3} \mathrm{PhC}_{6} \mathrm{H}_{3} \mathrm{CN}\right)$-adsorbed 4-phenyl-o-tolunitrile at $\mathrm{PhC}_{6} \mathrm{H}_{4} \mathrm{CN}$ formation on the slow stage 28) is determined by the equation (49).

$$
W_{6}=k_{28}\left[\Lambda\left(\mathrm{CH}_{3} \mathrm{PhC}_{6} \mathrm{H}_{3} \mathrm{CN}\right)\right]=k_{28} K_{26} P_{I I}
$$

Furthermore,

$$
W_{6}=k_{28} K_{26} P_{I I} / 1+K_{25} / K_{26} P_{I}
$$

Hence,

$$
\begin{aligned}
& \kappa_{6}=k_{28} K_{26} \\
& a=K_{25} / K_{26}
\end{aligned}
$$

Here $a$ is a constant reflecting ratio of the constants of adsorption equilibrium of 4-phenyl-o-xylene and 4phenyl-o-tolunitrile.

\section{Conclusions}

1) Ensuing from the proposed stage schemes of 4-phenyl-o-xylene ammoxidation mechanism, kinetic equations are in qualitative agreement with experimental data.

2) In deriving of the equations, physical meaning of a number of constants appearing in them is revealed.

3) The mechanism of formation of the main products as in the competing ways and its mutual transformation in each other are discussed.

4) The mechanism shows that the adsorbed 4-phenyl-o-xylol fragment as the general activated complex in interaction with $\mathrm{ZNH}_{3}$ forms 4-phenyl-o-tolunitrile, which in its turn transforms in 4-pfenylftalonitrile and in the case of interaction with $\mathrm{ZO}_{2}$ forms 4-pfenylftalimide. 
5) Conducted research provides an opportunity to create an effective single technological process of obtaining 4-pfenylftalonitrile, by the ammoxidation reaction of 4-phenyl-o-xylene.

\section{Acknowledgements}

Used in this work software package OptimMe was developed by the support of Science Foundation of "SOCAR" under the grant project ET-27 (15/10/2014) at the Institute of Catalysis and Inorganic Chemistry named after Acad. M. F. Nagiyev.

\section{References}

[1] Bagirzade, G.A. (2012) Preparation of 4-Phenylphthalonitrile by Vapor-Phase Ammoxidation of 4-Phenyl-o-Xylene: Reaction Kinetics. Petroleum Chemistry, 52, 105-112. http://dx.doi.org/10.1134/S0965544112020028

[2] Bagirzade, G.A., Tagiyev, D.B. and Manafov, M.R. (2014) Synthesis of 4-Phenylphthalo-nitrile by Vapor-Phase Catalytic Ammoxidation of Intermediate 4-Phenyl-o-Tolu-nitrile: Reaction Kinetics. Modern Research in Catalysis, 3, 6-11. http://dx.doi.org/10.4236/mrc.2014.31002

[3] Bagirzade, G.A. (2012) On Sequence of Activation of Methyl Groups of 4-Phenyl- and 4-Brom-o-Xylenes at the Heterogeneous Catalytic Oxidative Ammonolysis. Izvestia Vysshykh Uchebnykh Zavedeniy Khimia I Khimicheskay Tekhnologia, 55, 23-27.

[4] Bagirzade, G.A., Tagiyev, D.B., Sheinin, V.E. and Magerramova, Z.Y. (2013) Kinetic Model of Oxidative Ammonolysis of 4-Phenyl-o-Xylene. Azerbaijan Chemical Journal, 3, 47-54.

[5] Pat 632702 Belg (1963) Production of Aromatic Nitriles. Chemical Abstracts, 61, 3032 h.

[6] Shapovalov, A.A., Koshel, S.G., Sembaev, D.Kh., Postanova, M.V. and Koshel, G.N. (1999) Vapor-Phase Oxidation and Ammoxidation of Some Methyl Derivatives of Biphenyl. Russian Journal of Applied Chemistry, 72, 1315-1319.

[7] Bagirzade, G.A., Tagiyev, D.B. and Fatullayeva, S.S. (2014) Transformation Pathways of o-Xylene and Its 4-Substituted Derivatives in the Course of Vapor-Phase Oxidative Ammonolysis. Russian Journal of Applied Chemistry, 87, 1674-1679. http://dx.doi.org/10.1134/S1070427214110172

[8] Bagirzade, G.A. (2011) Resource-Saving and Power-Efficient Technologies in Chemical and Petrochemical Industries. Abstracts of Papers of III International Conference of the Mendeleev Russian Chemical Society, D. Mendeleev University of Chemical Technology of Russia, Moscow, 133-135. (In Russian)

[9] Bagirzade, G.A. and Tagiyev, D.B. (2012) Chemical Technology and Biotechnology of New Materials and Products. Abstracts of Papers of IV International Conference of the Mendeleev Russian Chemical Society, D. Mendeleev University of Chemical Technology of Russia, Moscow, 9-11. (In Russian)

[10] Bagirzade, G.A., Sheinin, V.E. and Magerramova, Z.Y. (2009) Resource- and Energy-Saving Technology in the Chemical and Petrochemical Industry. Abstracts of Papers of I International Conference of the Mendeleev Russian Chemical Society, D. Mendeleev University of Chemical Technology of Russia, Moscow, 94-95. (In Russian)

[11] Bagirzade, G.A. (2010) Innovative Chemical Technologies and Biotechnologies of Materials and Products. Abstracts of Papers of II International Conference of the Mendeleev Russian Chemical Society, D. Mendeleev University of Chemical Technology of Russia, Moscow, 197-198. (In Russian)

[12] Bagirzade, G.A. and Tagiyev, D.B. (2013) Resources- and Energy-Saving Technologies in the Chemical and Petrochemical Industry. Abstracts of Papers of V International Conference of the Mendeleev Russian Chemical Society, D. Mendeleev University of Chemical Technology of Russia, Moscow, 56-58. (In Russian)

[13] Plemenkov, V.V. (1997) Electronic and Steric Structure of Monofunctional Cyclo-Propanes. Russian Journal of Organic Chemistry, 33, 849-859.

[14] Palm, V.A. (1974) Introduction to Theoretical Organic Chemistry. Higher School, Moscow. (In Russian)

[15] Bagirzade, G.A. (2009) On the Reactivity of o-Xylene and It 4-Substituted at the Heterogeneous Catalytic Oxidative Ammonolysis. Izvestia Vysshykh Uchebnykh Zavedeniy Khimia I Khimicheskay Tekhnologia, 52, 47-49.

[16] Ravdel, A.A. and Ponomarevf, A.M. (1983) Short Handbook of Chemical-Physical Parameters. Khimiya, Leningrad. (In Russian)

[17] Rizayev, R.G., Scheinin, V.E., Allahkulu, A.O. and Avetisov, A.K. (1985) Kinetics of Oxidative Ammonolysis of oXylene I. Transformations of o-Xylene and o-Tolunitrile. Kinetics and Catalysis, 26, 345-348.

[18] Rizayev, R.G., Scheinin, V.E., Allahkulu, A.O. and Avetisov, A.K. (1986) Kinetics of Oxidative Ammonolysis of o-Xylene II. Formation of By-Products. Kinetics and Catalysis, 27, 339-345.

[19] Bagirzade, G.A. (2010) Kinetics of Oxidative Ammonolysis of 4-Brom-o-Xylene I. Transformations of 4-Brom-oXylene and 4-Brom-o-Tolunitrile. Russian Journal of General Chemistry, 80, 1672-1676. http://dx.doi.org/10.1134/S1070363210080177 
[20] Bagirzade, G.A. (2010) Kinetics of Oxidative Ammonolysis of 4-Brom-o-Xylene II. Formation of By-Products. Russian Journal of General Chemistry, 80, 1779-1785. http://dx.doi.org/10.1134/S1070363210090100

[21] Bagirzade, G.A. (2013) Kinetics of Oxidative Ammonolysis of 4-Brom-o-Xylene III. Transformation of 4-Brom-0Tolunitrile as Substrate. Russian Journal of General Chemistry, 83, 492-495. http://dx.doi.org/10.1134/S1070363213030158

[22] Bagirzade, G.A. (2014) Kinetics of Oxidative Ammonolysis of 4-Brom-o-Xylene IV. Mechanism of Formation of the Reaction Products. Russian Journal of General Chemistry, 84, 1079-1084. http://dx.doi.org/10.1134/S1070363214060048

[23] Bagirzade, G.A. and Tagiyev, D.B. (2014) Kinetics of Oxidative Ammonolysis of 4-Brom-o-Xylene V. Syntesis of 4Bromphtalonitrile. Russian Journal of General Chemistry, 84, 1085-1090.

[24] Rizayev, R.G., Mamedov, E.A., Scheinin, V.E. and Vislovsky, V.P. (1992) Heterogeneous Catalysis in the Production of Aromatic Nitriles. Elm, Baku. (In Russian)

[25] Golodets, G.I. (1985) Some Problems in the Theory of Heterogeneous Catalytic Partial Oxidation. Problems of Kinetics and Catalysis, 19, 28-58.

[26] Sokolovsky, V.D. (1985) Mechanism of Selective Ammoxidation of Lower Paraffins. Problems of Kinetics and Catalysis, 19, 99-119.

[27] Sadovsky, A.S. and Gelbshteyn, A.I. (1985) Propylene Ammoxidation (Mechanism and Kinetics Questions). Problems of Kinetics and Catalysis, 19, 119-131.

[28] Kiperman, S.L. (1979) Fundamentals of Chemical Kinetics in Heterogeneous Catalysis. Khimiya, Moscow. (In Russian) 